\title{
Blucher
}

Blucher Proceedings

Cuba e Brasil no Século XXI (CBS21)

Desafíos Estratégicos e Institucionais da Inovação

\section{Ciência, Tecnologia e Inovação no Brasil: breve panorama e possíveis áreas de colaboração com Cuba}

\author{
Dr. Sergio Machado Rezende ${ }^{1}$
}

\section{Introdução}

Na história do Brasil, colonização e império somaram quase 400 anos, durante os quais o País não tinha universidades. Os primeiros cursos de direito e medicina foram criados somente depois que a família real portuguesa veio para o Brasil em 1808. Até então a Coroa Portuguesa não permitia que sua colônia tivesse cursos superiores. No Século XIX, quando Cuba, Chile e Argentina, dentre outros países da América Latina, já tinham universidades, foi que o Brasil criou escolas e faculdades de ensino superior. Mas somente em 1934 foi implantada a primeira universidade de verdade, a Universidade de São Paulo. Até a década de 1960 uma parcela muito pequena da população tinha acesso ao ensino superior no Brasil. Com raras excessões, os professores das faculdades e escolas exerciam atividades profissionais em outras áreas, não eram pesquisadores, dentre outras razões porque não havia nas universidades emprego em regime de tempo integral. E tampouco havia programas de formação pós-graduada. Também não havia engenheiros ou especialistas em setores básicos da indústria, nosso parque industrial era incipiente e não existia cultura de inovação nas empresas.

As bases para a mudança deste quadro foram lançadas em 1951 com a criação do Conselho Nacional de Pesquisas (CNPq) e da Coordenação de Aperfeiçoamento

\footnotetext{
${ }^{1}$ Ciência, Tecnologia e Inovação no Brasil: breve panorama e possíveis áreas de colaboração com Cuba. Sergio Machado Rezende, Professor Titular de Física da Universidade Federal de Pernambuco, Recife, Brasil. Foi Ministro da Ciência e Tecnologia do Brasil no período 2005-2010, no Governo de Luiz Inácio Lula da Silva. E-mail: rezende@df.ufpe.br.
} 
de Pessoal de Nível Superior (CAPES). CNPq e CAPES passaram a conceder bolsas de estudos para formação pós-graduada no exterior e a apoiar as atividades científicas nos pequenos grupos de pesquisa que estavam sendo criados. A atuação do CNPq e da CAPES foi fundamental para a mudança do cenário de Ciência e Tecnologia (C\&T) no Brasil, que nas últimas décadas pode ser caracterizado por três períodos distintos: 1- A construção e expansão do Sistema Nacional de Ciência, Tecnologia e Inovação (SNCTI) no período 1960-1990; 2- Crise e transição para uma nova sistemática de financiamento em 1991-2003; 3- Implantação de uma política federal de C\&T mais consistente no período 2003-2010.

\section{Sistema Nacional de C\&T no Brasil}

A construção do Sistema Nacional de C\&T no Brasil se deu durante as décadas de 1960, 1970 e 1980, quando CNPq, CAPES, BNDE e a Financiadora de Estudos e Projetos (FINEP), esta criada em 1967, implantaram diversas modalidades de apoio financeiro para C\&T. O CNPq concedia bolsas de iniciação científica, para estudantes de graduação, mestrado e doutorado, para estudantes de pósgraduação, e bolsas de pesquisa para pesquisadores como complementação salarial não tributável. Também apoiava financeiramente projetos de pesquisa, realização de eventos (congressos, conferências) e viagens ao exterior. Por outro lado a CAPES dedicava a maior parte de seu esforço para apoiar os programas de pósgraduação, basicamente através da concessão de bolsas de mestrado e doutorado, como também desenvolvia uma competente sistemática de credenciamento e avaliação dos cursos de pós-graduação. O BNDE, e posteriormente a FINEP, com o novo Fundo Nacional de Desenvolvimento Científico e Tecnológico (FNDCT), criado em 1971, concediam financiamentos não-reembolsáveis para centros, institutos ou departamentos acadêmicos. Estes apoios institucionais, como eram conhecidos, previam recursos para obras e reformas físicas, aquisição de equipamentos, material permanente e de consumo e outros custeios das atividades de pesquisa e pós-graduação, inclusive pagamento de pessoal de apoio.

Ao ser criado em 1985, o Ministério da Ciência e Tecnologia (MCT) absorveu em sua estrutura a FINEP, o CNPq e suas unidades de pesquisa. O MCT conseguiu recuperar, parcialmente, os recursos do FNDCT que haviam sido reduzidos substancialmente em relação aos maiores níveis da década de 1970. Adicionalmente, a primeira gestão do MCT conquistou outros avanços importantes, como o aumento do número de bolsas de pós-graduação no CNPq e a implementação do Programa de Formação de Recursos Humanos em Áreas Estratégicas (RHAE). As dificuldades para a recuperação plena dos orçamentos do FNDCT levaram o MCT a criar um novo instrumento de financiamento, o Programa de Apoio ao Desenvolvimento Científico e Tecnológico (PADCT), com recursos de empréstimos do Banco Mundial (BIRD) e contrapartidas do Tesouro Nacional. Ele vigorou de 
1985 à 1998, apoiando projetos de pesquisa selecionados por meio de editais em algumas áreas de conhecimento consideradas estratégicas para o desenvolvimento científico e tecnológico, tais como Química e Engenharia Química, Biotecnologia, Geociências e Novos Materiais.

O final da década de 1980 e o início dos anos 1990 foram caracterizados por grande instabilidade na estrutura de gestão de C\&T do Governo Federal, tendo o MCT sido extinto e recriado mais de uma vez. Apesar disto e da irregularidade dos recursos para bolsas e fomento, os instrumentos de financiamento da FINEP e do CNPq foram mantidos em sua essência. Porém, no meio da década de 1990 o número de bolsas passou a diminuir a cada ano enquanto o programa de auxílios à pesquisa foi interrompido em 1997. Nesse mesmo ano, a FINEP rescindiu os convênios institucionais em vigor, face à drástica redução dos recursos do FNDCT. Em 1999, o PADCT, que já se encontrava em sua terceira versão, foi desativado, apesar de haver saldo nos recursos do empréstimo do BIRD. A crise nas agências federais de C\&T só não causou maior prejuízo ao Brasil porque no estado de São Paulo, que concentrava cerca de $50 \%$ dos pesquisadores do País, a Fundação de Amparo à Pesquisa do Estado de São Paulo (FAPESP) dispunha de recursos significativos para fomentar a pesquisa. Isto levou à uma concentração ainda maior da ciência naquele estado.

Os anos 1996-2003 podem ser caracterizados como um período de transição: por um lado, as contingências econômicas levaram o MCT a interromper os programas tradicionais de financiamento, mas, por outro, o Ministério lançou as bases para o processo de reconstrução da política de C\&T. Isto foi feito com a criação de novas modalidades e formatos de financiamento e, principalmente, novos mecanismos para assegurar fontes de recursos mais estáveis para o setor. A modalidade de apoio financeiro a projetos de pesquisa submetidos espontaneamente ao CNPq por líderes de grupos, em calendário anual, foi substituída por três programas, implementados no período de 1996-2000. O primeiro foi o Programa de Apoio a Núcleos de Excelência (PRONEX), concebido com base na idéia de que os recursos para a pesquisa estavam sendo fragmentados. Ele objetivava proporcionar apoio financeiro continuado apenas aos grupos de pesquisa de alta competência, que tivessem liderança e papel nucleador em suas áreas de atuação. Entre 1996 e 1998 foram selecionados 206 núcleos de excelência, mas na época o número de grupos de pesquisas cadastrados no Diretório de Grupos do CNPq era de cerca de 10 mil. O segundo foi o Programa Institutos do Milênio, usando recursos do Banco Mundial remanescentes do PADCT e inspirado no programa chileno. A reação da comunidade científica a esta concentração de recursos em poucas instituições levou o CNPq a lançar, em 2000, um Edital Universal para selecionar projetos apresentados por líderes de grupos de pesquisa, concorrendo ao financiamento em três categorias de valores limites, mas sem calendário pré-estabelecido. O 
avanço mais importante no setor de C\&T no período 1999-2002 foi a criação dos Fundos Setoriais de Ciência e Tecnologia. Estes fundos foram estabelecidos por leis aprovadas pelo Congresso Nacional destinando para eles percentuais da receita da exploração de recursos naturais pertencentes à União e de parcelas de impostos federais de certos setores. Uma medida muito importante foi a incorporação desses fundos ao FNDCT, o que permitiu sua gradual recuperação e posterior expansão.

\section{Política Nacional e Plano de Ação de CT\&I}

A partir de 2003 o governo federal tomou duas iniciativas que mudaram muito o quadro de C\&T no Brasil, a definição de uma Política Nacional de CT\&I em 2004 e o lançamento de um Plano de Ação de CT\&I (PACTI) em 2007. O PACTI proporcionou muitos avanços no cenário de C,T\&I do País, porém é preciso destacar os três mais importantes: (1) o grande aumento nos recursos financeiros federais para CT\&I, que alavancaram os recursos de governos estaduais, possibilitando ampliar a formação de recursos humanos e o financiamento adequado da pesquisa básica e aplicada em todas as áreas do conhecimento e em todos os níveis da estrutura do Sistema Nacional de CT\&I, desde os projetos de pesquisadores individuais e de grupos de pesquisa até programas de redes de pesquisa e de grandes instituições; (2) grande avanço no marco legal de CT\&I, promovidos por leis aprovadas pelo Congresso Nacional e por Assembléias Legislativas Estaduais, por decretos presidenciais e portarias de ministérios, que juntamente com a forte articulação entre o governo federal e governos estaduais, contribuiu para a consolidação do Sistema Nacional de CT\&I; e (3) notável avanço no ambiente para inovação tecnológica nas empresas, proporcionado pela criação de um amplo leque de instrumentos para financiar projetos de empresas, operados pela FINEP e pelo BNDES, por novos incentivos fiscais, pela criação do Sistema Brasileiro de Tecnologia (SIBRATEC) e pela mobilização de empresas e entidades empresariais.

O PACTI tinha quatro prioridades estratégicas, norteadas pela Política Nacional de CT\&I: I- Expansão e Consolidação do Sistema Nacional de Ciência, Tecnologia e Inovação; II- Promoção da Inovação Tecnológica nas Empresas; III- Pesquisa, Desenvolvimento e Inovação em Áreas Estratégicas; e IV- Ciência, Tecnologia e Inovação para o Desenvolvimento Social. Estas prioridades estavam expressas em 21 linhas de ação que compreendiam 87 programas, todos com objetivos claros, institucionalidade, metas e orçamentos.

Em todas quatro prioridades os resultados alcançados foram expressivos. $\mathrm{Na}$ Prioridade I os principais resultados foram: (1) forte aumento da articulação entre o Governo Federal e os Estados contribuindo para consolidar o Sistema Nacional de CT\&I; (2) ampliação das ações e iniciativas de cooperação internacional em C\&T; (3) aumento considerável no número de bolsas de estudo e de pesquisa do CNPq e da CAPES; (4) forte ampliação dos recursos e das modalidades de financiamento 
da pesquisa científica e tecnológica e com boa distribuição geográfica; (5) conclusão da conexão à Internet em alta velocidade de todas universidades, escolas técnicas e instituições de pesquisa do País através da Nova RNP (Rede Nacional de Pesquisa).

Contribuíram muito para a abrangência e capilaridade das ações do MCT e de suas agências a articulação e as parcerias com os Estados, por meio, principalmente, de suas Secretarias de Ciência e Tecnologia e Fundações de Amparo à Pesquisa (FAPs). As principais ações e iniciativas executadas em cooperação com os Estados foram: (1) a celebração de acordos de cooperação técnico-científica com todos os estados da Federação; (2) o fortalecimento do Programa de Núcleos de Excelência (PRONEX); e (3) o lançamento do Programa Institutos Nacionais de Ciência e Tecnologia (INCTs), cujo edital contou com o maior volume de recursos estaduais disponibilizados até hoje para parcerias; iv- ampliação do Programa de Apoio à Pesquisa na Pequena Empresa (PAPPE), em parceria com as FAPs, para concessão de subvenção econômica para empresas. Adicionalmente, foram feitos esforços para os estados implementarem suas leis estaduais de inovação, existentes hoje na grande maioria dos estados da federação.

Para a consolidação do Sistema Nacional de CT\&I, o MCT dedicou grande esforço para promover e facilitar a interação entre os diversos segmentos que o compõem. Destacam-se, aqui, a intensa articulação com, dentre outras, a Academia Brasileira de Ciências (ABC), a Sociedade Brasileira para o Progresso da Ciência (SBPC), a Associação Nacional dos Dirigentes das Instituições Federais de Ensino Superior (ANDIFES), o Conselho Nacional de Secretários Estaduais para Assuntos de C,T\&I (CONSECTI), o Conselho Nacional das Fundações de Amparo à Pesquisa (CONFAP), o Fórum dos Secretários Municipais de Ciência e Tecnologia, a Confederação Nacional da Indústria (CNI) e diversas Associações Empresariais Setoriais.

No âmbito federal o PACTI articulou-se fortemente com a Política de Desenvolvimento Produtivo (PDP); o Plano de Desenvolvimento da Educação (PDE); a Política de Desenvolvimento da Agropecuária (PDA); o Programa Mais Saúde e a Política Nacional de Defesa. É importante destacar também os avanços na interação do PACTI com o Programa de P\&D da Petrobras e com os programas de apoio à inovação do BNDES, mediante os instrumentos da PDP.

Um dos resultados importantes dentro da Prioridade I do PACTI foi o considerável aumento do número de bolsas do CNPq e da CAPES para estudantes, desde a iniciação científica até a pós-graduação, como também para pesquisa. Como mostra a Figura (1), o número de bolsas das duas agências evoluiu de 77.579 em 2001 para 149.579 em 2009 e os recursos correspondentes passaram de $\mathrm{R} \$ 813$ milhões para $\mathrm{R} \$ 2$ bilhões no mesmo período. Cabe notar que as linhas na Figura 1 representam as projeções do PACTI enquanto os símbolos representam os números efetivamente implementados. Vê-se que a execução do CNPq tem sido 
aquém do planejado em 2007, porém isto foi compensado pelo expressivo aumento do número de bolsas da CAPES. Ao final de 2010 tinha sido alcançada a meta de 160 mil bolsas estabelecida no PACTI.

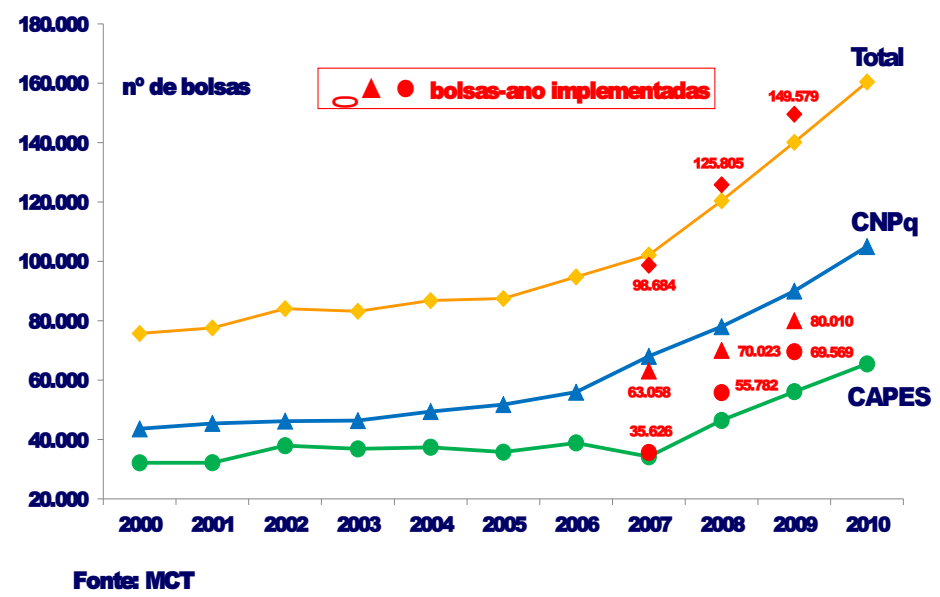

Figura 1: Número de bolsas-ano do CNPq, CAPES e total.

Outro dado importante diz respeito ao contínuo crescimento na formação de recursos humanos pós-graduados, com titulação de mestre e doutor, mostrado na Figura 2. Chama a atenção o fato de que em 24 anos o número de mestres e doutores formados por ano cresceu por um fator superior a dez, passando de cerca de 5 mil em 1987 para 55 mil em 2011. Isto está sendo decisivo para a formidável expansão da comunidade científica que era insignificante em 1960 e ultrapassou 150 mil pesquisadores em atividade no ano de 2010, sendo mais de 85 mil doutores. Vale frisar, entretanto, que o número de pesquisadores por habitantes é ainda baixo, cerca de 8 por 10 mil habitantes, o que corresponde a um terço da proporção nos países industrializados. A continuidade na expansão do número de pesquisadores é um dos grandes desafios do país para a próxima década.

A Tabela 1 mostra a distribuição dos doutores em atividade nas universidades e centros de pesquisa no Brasil em 2009. São 253 universidades e 113 centros de pesquisa ou institutos tecnológicos, que em 2009 contavam com cerca de 85 mil doutores. Um dos desafios mais importantes identificados em 2007 para o PACTI foi a ampliação dos recursos e a organização e sistematização dos vários instrumentos para financiar adequadamente a melhoria da infraestrutura de pesquisa e a realização de projetos de pesquisa científica e tecnológica, de pesquisadores individuais, grupos de pesquisa, redes temáticas e instituições maiores. É com satisfação 
que constatamos que este desafio foi vencido, com a ampliação dos recursos e a articulação das agências do MCT, FINEP e CNPq, com a CAPES, ministérios e entidades federais e com as FAPs estaduais.

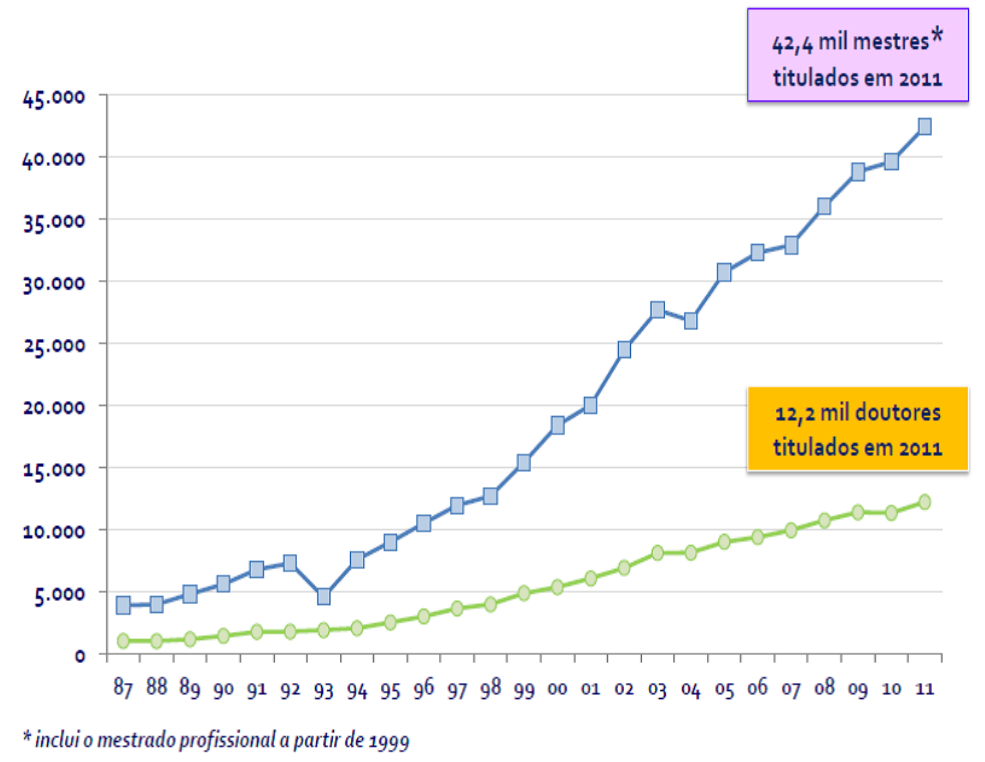

Figura 2: Número de mestres e doutores titulados por ano (Fonte: CAPES).

Na segunda metade da década de 2000, o CNPq passou a dispor de editais em programas que apóiam projetos numa larga faixa da estrutura de pesquisa. O Edital Universal, lançado anualmente, é a maior iniciativa do $\mathrm{CNPq}$ para apoiar projetos de pesquisa de indivíduos e grupos, para o qual podem ser apresentadas propostas em qualquer área do conhecimento. Naquela época o valor do Edital Universal foi substancialmente ampliado com recursos provenientes do FNDCT. O $\mathrm{CNPq}$ também passou a lançar anualmente editais voltados exclusivamente para as áreas de ciências humanas e sociais. De 2007 a 2010 estes editais totalizaram cerca de $\mathrm{R} \$ 500$ milhões e selecionaram cerca de 11 mil projetos.

Além desses editais transversais, o $\mathrm{CNPq}$ passou a lançar uma grande variedade de editais para selecionar projetos em temas específicos, numa vasta gama de áreas de C\&T, apoiados com recursos dos Fundos Setoriais e também do orçamento próprio. Também lançou editais para selecionar propostas para realização de eventos, intercâmbio de pesquisadores em programas de cooperação internacional e divulgação e melhoria do ensino de ciências. No total, entre 2007 e 2010 o CNPq lançou 198 editais, disponibilizando $\mathrm{R} \$ 2,53$ bilhões, tendo sido selecionadas quase 40 mil propostas.

Um programa importante criado na década de 90 que foi revigorado e ampliado 
Tabela 3: Distribuição de doutores nas universidades e centos de pesquisa no País (Fonte: Diretório de Pesquisa do CNPq, 2009. Compiladas somente instituições com mais de 10 doutores)

\begin{tabular}{|c|c|c|}
\hline Insituições & Quantidades & Doutores \\
\hline \hline Universidades & $\mathbf{2 5 3}$ & $\mathbf{7 7 . 4 6 3}$ \\
\hline \hline Federais & 77 & 39.737 \\
Estaduais & 39 & 24.236 \\
Municipais & 6 & 542 \\
Privadas & 131 & 12.948 \\
\hline \hline Centros de Ciência e P\&D & $\mathbf{1 1 3}$ & $\mathbf{8 . 0 9 9}$ \\
\hline \hline Federais & 62 & 4.003 \\
Estaduais & 31 & 3.787 \\
Outras & 10 & 309 \\
\hline \hline
\end{tabular}

pelo CNPq é o PRONEX - Programa de Apoio a Núcleos de Excelência, que apóia núcleos de pesquisa formados por grupos de reconhecida excelência e articulados em redes temáticas. Em 2008 ele foi ampliado com recursos do FNDCT e passou a ser executado em parceria com FAPs estaduais, que também aportam recursos de contrapartida e lançam os editais com âmbito estadual. Atualmente há mais de 250 Núcleos de Excelência financiados em 15 estados com recursos aprovados que totalizam $\mathrm{R} \$ 160$ milhões.

O maior programa da história do $\mathrm{CNPq}$ foi criado em 2008. Trata-se dos Institutos Nacionais de Ciência e Tecnologia (INCTs), selecionados em processo competitivo para substituir os Institutos do Milênio. O programa Institutos do Milênio, criado em 2001, visava promover a formação de redes de pesquisa em todo território nacional e a excelência científica e tecnológica e o fortalecimento de grupos de pesquisa em qualquer área do conhecimento, assim como em áreas definidas como estratégicas. Por diversas razões os Institutos do Milênio não chegaram a ter a importância e a dimensão planejadas. Por esta razão, como decorrência do PACTI, eles deram lugar aos INCTs, caracterizados por uma sede em instituição de excelência na pesquisa e no ensino e atuando em rede temática com instituições em outras regiões do território nacional. O programa, coordenado pelo $\mathrm{CNPq}$, foi articulado e co-financiado com a FINEP (FNDCT), Ministério da Saúde, CAPES, BNDES, Petrobras, e Fundações Estaduais de Amparo à Pesquisa de SP, RJ, MG, SC, PA, AM, PI e RN. O Edital do CNPq de 2008 selecionou 122 INCTs, com recursos totalizando $\mathrm{R} \$ 609$ milhões. Estes INCTs congregam os melhores grupos de pesquisa em áreas de fronteira da ciência e em áreas estratégicas para o desenvolvimento do país e estão contribuindo para tornar a pesquisa científica e 
tecnológica no País mais competitiva internacionalmente. A Figura 3 mostra o número de sedes de INCTs por estado e demonstra a boa distribuição geográfica deles.

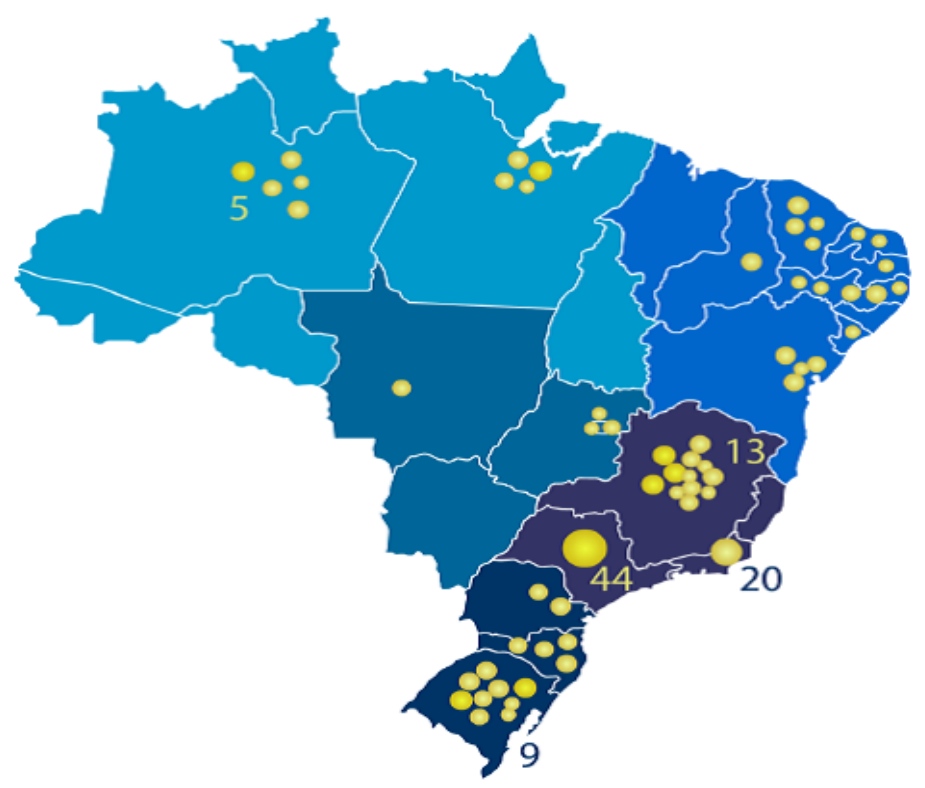

Figura 3: Distribuição das sedes de INCTs por estado.

A Figura 4 apresenta a evolução dos recursos do CNPq e do FNDCT investidos nos programas de apoio à pesquisa mencionados. No caso do INCT, não estão incluídos os recursos dos parceiros, MS, CAPES, BNDES, Petrobras e FAPs. Sem dúvida, a ampliação dos recursos para financiar a pesquisa científica e tecnológica foi formidável nos 8 anos do Governo Lula.

O financiamento de projetos de pesquisa e de infra-estrutura, também feito pela FINEP com recursos do FNDCT, primordialmente com seleção de propostas através de editais do FNDCT/Fundos Setoriais. Enquanto o CNPq concedia recursos a indivíduos, com compromissos firmados por meio de termos de concessão, a FINEP financiava instituições por meio de convênios. Dentre os editais destacam-se aqueles que fazem parte do PROINFRA - Programa de Modernização da Infraestrutura das ICTs, financiado com recursos do CT-Infra. O PROINFRA passou a fazer parte do calendário das universidades e entidades de pesquisa do País, com edital lançado em dezembro de cada ano para seleção de porpostas em maio-junho. De 2006 a 2010 os editais do PROINFRA selecionaram propostas que totalizaram cerca de $\mathrm{R} \$ 1$ bilhão, que tiveram grande impacto na melhoria e expansão das intalações de pesquisa das universidades e entidades públicas do País. 


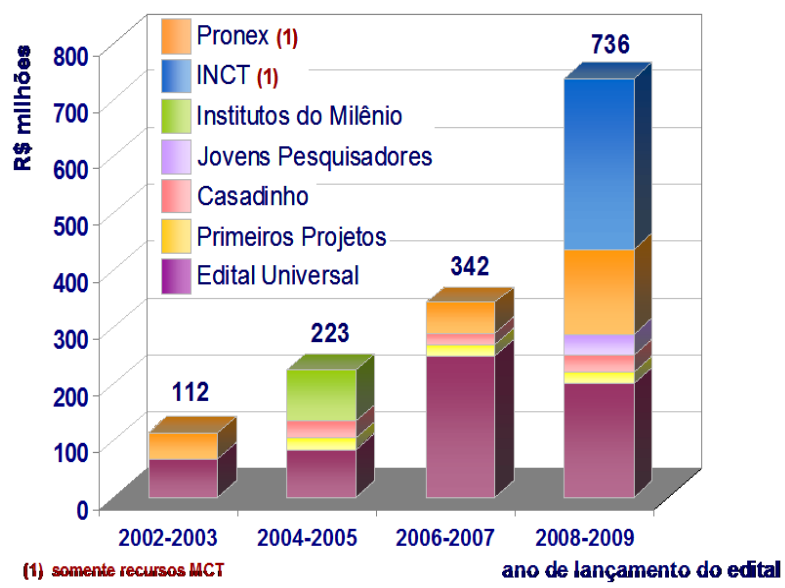

Figura 4: Evolução dos recursos de programas de apoio à pesquisa em todas as áreas do conhecimento (CNPq)

O PACTI contribuiu muito para expandir e melhorar a qualidade dos programas de pós-graduação (PG) no País. Neste processo a CAPES desempenha papel importantíssimo com seu sistema de avaliação da PG. Ela tem uma diretoria com a finalidade específica de avaliar os programas, feito por cerca de 50 comissões das diversas áreas do conhecimento. Formadas por membros da comunidade científica, as comissões avaliam todos os programas de PG do País. Com base em levantamentos periódicos, as comissões utilizam informações qualitativas e indicadores objetivos dos programas para atribuir a cada um deles um conceito que varia de 1 a 7 , sendo 7 o mais elevado. Programas que recebem conceitos 3 ou inferior repetidamente são descredenciados pela CAPES. Somente programas com mestrado e doutorado podem receber conceitos 6 e 7, com os quais são considerados de nível internacional. A Figura 5 mostra a distribuição, por grande área, dos 320 programas que receberam conceitos 6 e 7 na avaliação de 2010, dentre cerca de 3 mil programas existentes na época. Chama a atenção que em apenas quatro décadas o Brasil construiu um sistema de formação pós-graduada com um número expressivo de programas de bom nível em todas as áreas do conhecimento.

O PACTI também contribuiu muito para consolidar e expandir os resultados alcançados pelo Brasil em relação à sua produção científica. Isto pode ser verificado pelo número de artigos científicos publicados em revistas indexadas. De 2000 a 2009 o número de publicações de entidades brasileiras aumentou 205\%, atingindo cerca de 32.100 artigos indexados na base de dados National Science Indicators, da Thomson Reuters Scientific. Assim, a participação do Brasil na produção científica mundial dobrou naquele período. Em 2008 o País alcançou a $13^{a}$ colocação no ranking mundial da produção científica, ultrapassando Rússia e Holanda, países 


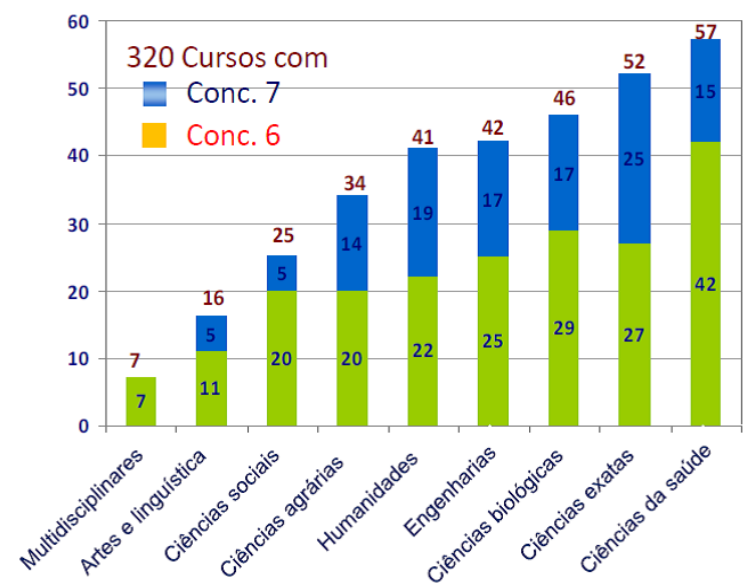

Figura 5: Distribuição por grande área dos programas de pós-graduação com conceitos 6 e 7 atribuidos pelo sistema de avaliação da CAPES em 2010.

com grande tradição em ciência. O ritmo de crescimento da produção científica brasileira tem se mostrado bem mais elevado do que o da produção mundial, como mostra a Figura 6.

Enfim, pode-se constatar que apesar do início tardio na formação de mestres e doutores, o País avançou muito em seu sistema de C\&T. Nossa comunidade científica já tem mais de 150 mil pesquisadores. Nossa produção científica cresce há três décadas mais que o do restante do mundo. O número de artigos publicados em revistas indexadas, que em 1981 era de 0,44\% do total do mundo, em 2009 atingiu $2,7 \%$.

Apesar do grande avanço da ciência no País, a inovação tecnológica nas empresas brasileiras ainda é tímida. Segundo o IBGE, das 70 mil empresas industriais existentes em 2005 somente $3 \%$ tinham introduzido um produto novo no mercado. Menos de 5atuam em empresas. Esta situação decorre da falta de cultura de inovação no ambiente empresarial e também da pouca articulação das políticas industrial e de C\&T. Até 2005, o principal instrumento para apoiar inovação nas empresas era a linha de crédito da FINEP com juros de TJLP mais 5\%.

Por esta razão, a Prioridade II do PACTI, Promoção da Inovação Tecnológica nas Empresas, constituiu um dos grandes desafios para o Plano. A inovação nas empresas passou a ser a principal prioridade comum da Política de Desenvolvimento Produtivo (PDP) e do Plano de Ciência, Tecnologia e Inovação 2007-2010 (PACTI). Por outro lado, as entidades empresariais, federações de indústria, associações setoriais e o SEBRAE, abraçaram a causa de colocar a inovação na agenda das empresas e têm liderado iniciativas importantes nessa direção. 


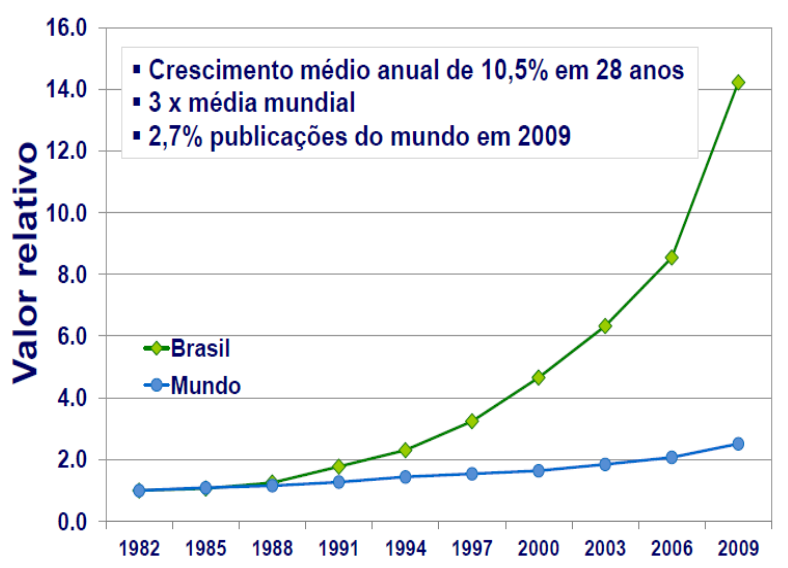

Figura 6: Crescimento relativo da produção científica no Brasil e no mundo, com referência a 1982 (Fonte: base de dados National Science Indicators - NSI, editada pela Thomson Reuters Scientific INC, 2009; a partir de tabulação da CAPES).

\section{Cenário Atual para a Inovação no País}

Hoje, especialmente a partir da Lei de Inovação, aprovada em 2004, e da Lei do Bem, de 2005, há um novo cenário para a inovação no país, permitindo às empresas a utilização de um leque de instrumentos bem mais amplo e efetivo e estimulando a criação de novas empresas baseadas em tecnologia, as start-ups. A subvenção econômica, prevista na Lei de Inovação, administrada pela FINEP, viabilizou que recursos não reembolsáveis de cerca de $R \$ 2,0$ bilhões estejam sendo concedidos às empresas inovadoras, por meio de três programas: Edital Nacional da FINEP, PAPPE e PRIME, os dois últimos em parceria com os estados.

Os Editais Nacionais de Subvenção passaram a ser anunciados anualmente a partir de 2006. Até 2010 um total de $\mathrm{R} \$ 1.566$ milhões de recursos nãoreembolsáveis foram aportados para 825 projetos de empresas selecionados entre 8.890 propostas. Os editais focaram diferentes áreas tecnológicas, sendo priorizados os setores mais diretamente vinculados com a PDP, como biotecnologia, nanotecnologia, TICs, TV digital, fármacos e medicamentos, energias renováveis e aeroespacial. A partir de 2007, a área de desenvolvimento social, que antes estava inserida na parcela de 'temas gerais', ganhou destaque específico.

O Programa de Apoio à Pesquisa em Empresas (PAPPE) aportou recursos financeiros para as pequenas e médias empresas, por meio da operação com parceiros estaduais, para o desenvolvimento de atividades de inovação em setores importantes para o desenvolvimento local. Quatorze estados lançaram editais para contratação de projetos, tendo selecionado mais de 404 empresas. Os investimentos nesta modalidade da subvenção chegaram a $\mathrm{R} \$ 265$ milhões, sendo $\mathrm{R} \$ 150$ milhões 
do FNDCT e R $\$ 115$ milhões de contrapartida de FAPs, SEBRAE e Federações da Indústria. Em linhas gerais, são beneficiadas empresas que faturem até R $\$ 10,5$ milhões ao ano, com financiamentos entre $\mathrm{R} \$ 200$ mil e $\mathrm{R} \$ 400$ mil.

O Programa Primeira Empresa Inovadora (PRIME), que entrou em operação no início de 2009, concedeu subvenção econômica para start-ups. A operacionalização do PRIME foi feita em parceria com 17 incubadoras de empresas préselecionadas, e já apóia 1.381 empresas selecionadas por meio de editais regionais. Cada empresa recebeu em 2009 R $\$ 120$ mil de subvenção, totalizando um aporte de R $\$ 166$ milhões. Estas empresas poderão, no segundo ano, receber mais R $\$ 120$ mil em recursos reembolsáveis com juros subsidiados do Programa JURO ZERO. E muito importante, existem hoje mais de trinta fundos de capital de risco, criados com apoio da FINEP e do BNDES, com mais de $\mathrm{R} \$ 3$ bilhões para investir nas novas empresas inovadoras.

Além das operações não-reembolsáveis, já assinaladas, a FINEP passou a conceder apoio à inovação nas empresas por meio de operações reembolsáveis, a saber: Inova Brasil e Juro Zero. Substituindo o antigo Pró-Inovação, o Inova Brasil (Programa de Incentivo à Inovação nas Empresas Brasileiras) constitui-se em financiamento com encargos reduzidos para a realização de projetos de pesquisa, desenvolvimento e inovação nas empresas brasileiras, como suporte à PDP. Foram apoiados 166 projetos, com recursos que totalizaram $\mathrm{R} \$ 2,8$ bilhões, passando de $\mathrm{R} \$ 557,8$ milhões em 2007 para $\mathrm{R} \$ 1,7$ bilhão em 2009. Esses números aumentaram ainda mais desde então.

O Programa Juro Zero constitui-se em modalidade de financiamento para apoio a projetos ou planos de negócios desenvolvidos por micro e pequenas empresas inovadoras, em um período máximo de 18 meses, e que representem inovação em seu setor de inovação, seja nos aspectos comerciais, de processos ou de produtos e serviços. De 2007 a 2010 foram apoiados 47 projetos de empresas, com recursos de $\mathrm{R} \$ 36,7$ milhões.

De janeiro de 2007 a agosto de 2010, o desembolso do BNDES por meio das linhas de financiamento, dos programas de apoio à inovação e do crédito à aquisição de bens de capital de MPEs já totalizou R $\$ 5,2$ bilhões. Entre 2007 e 2009, esse desembolso cresceu na ordem de $36 \%$. A carteira atual de operações nas linhas e programas de apoio à inovação apresenta um montante de $\mathrm{R} \$ 7,3$ bilhões, incluindo-se nesse grupo as operações ativas contratadas - saldo a desembolsar, aprovadas, em análise, enquadradas, com consulta e em perspectiva.

Por sua vez, a Lei do Bem concede incentivos fiscais para empresas que realizem atividades de pesquisa tecnológica e de inovação. Relativo ao ano de 2006, 130 empresas declararam investimentos de aproximadamente $\mathrm{R} \$ 2,2$ bilhões. Já em 2007 saltaram para 300 empresas declarando mais de $\mathrm{R} \$ 5,1$ bilhões. Em 2008 o número de empresas saltou para 460 e os investimentos atingiram $\mathrm{R} \$$ 8,8 bilhões. 
Nesse mesmo período, o investimento em $\mathrm{P} \& \mathrm{D}$ das empresas que se beneficiaram da Lei do Bem evoluiu de 2,1 bilhões (0,09\% do PIB), em 2006, para 8,1 bilhões (0,28\% do PIB), em 2008, quase quadruplicando naqueles três anos.

O Programa Nacional de Apoio às Incubadoras de Empresas e Parques Tecnológicos (PNI) criado em 2004 foi outra importante iniciativa para a promoção do desenvolvimento tecnológico e da inovação nas micro e pequenas empresas, estimulando iniciativas de instalação e consolidação de incubadoras de empresas e parques tecnológicos. Em 2009, cerca de 8 mil empresas inovadoras, instaladas em 400 incubadoras de empresas localizadas em todo o País, geraram 35 mil empregos com faturamento total de cerca de $\mathrm{R} \$ 3,5$ bilhões. Os parques tecnológicos, por sua vez, são complexos de desenvolvimento econômico e tecnológico que fomentam e promovem sinergias nas atividades de pesquisas científicas e tecnológicas e de inovação entre as empresas e instituições científicas e tecnológicas, públicas e privadas, com forte apoio institucional e financeiro entre os governos federal, estadual, municipal, comunidade local e setor privado. Em 2009, existiam 74 iniciativas de parques tecnológicos, sendo 25 em operação, 17 em implantação e 32 em projeto.

O Programa RHAE-Pesquisador na Empresa é uma ação do CNPq para prover bolsas para pesquisadores, mestres e doutores, atuarem nas empresas. Em 2008, 131 empresas foram contempladas, possibilitando a inserção de 195 mestres e doutores, além de 180 técnicos para composição da equipe de trabalho. Com o acréscimo dos recursos no programa, em 2009, as 172 empresas selecionadas absorveram 312 mestres e doutores, e 378 técnicos. De 2008 a 2010, os recursos destinados ao programa foram da ordem de $\mathrm{R} \$ 76$ milhões e em 2011 alcançaram $\mathrm{R} \$ 40$ milhões.

Um importante estímulo para inovação nas empresas veio da Lei 12.349, sancionada pelo Presidente da República em dezembro de 2010. Ela alterou a Lei 8.666 que regulamenta as licitações públicas no país. Os novos dispositivos abriram a possibilidade de conceder margem de preferência nas licitações estatais às empresas brasileiras, especialmente às empresas que investem em pesquisa e desenvolvimento no País, em até $25 \%$. Esse instrumento é considerado central no desenvolvimento produtivo e tecnológico de setores como saúde, tecnologias da informação e de comunicação (TIC), defesa, e aeronáutico. A Lei 12.349 representou o alcance de uma das metas do PACTI e da PDP para possibilitar ao Estado a utilização de seu poder de compra para impulsionar o desenvolvimento de produtos e processos nas empresas brasileiras.

Para fomentar a imprescindível interação universidade-empresa, o Governo Federal implantou o Sistema Brasileiro de Tecnologia (SIBRATEC). Ele foi formado por 56 redes de grupos e núcleos de P\&D articuladas nacionalmente, sendo 14 redes de centros de inovação, 20 de serviços tecnológicos, e 22 de extensão, estas organizadas estadualmente. O SIBRATEC foi coordenado pelo MCT mas teve a 
participação ativa de vários ministérios e entidades federais como FINEP, BNDES e INMETRO. As redes de extensão têm a missão primordial de apoiar a inovação nas micro e pequenas empresas, e por isso mesmo têm uma articulação crescente com o SEBRAE. As redes de serviços tecnológicos fazem com que a metrologia de qualidade e laboratórios de análise de conformidade de produtos e processos dêem suporte à produção no complexo campo das disputas comerciais.

Para consolidar o processo iniciado com o SIBRATEC, em 2011 o governo criou a Empresa Brasileira de Pesquisa e Inovação Industrial-EMBRAPII, que inspirada no papel da EMBRAPA tem a missão de acelerar o processo de inovação industrial, articulando o sistema nacional de P\&D com as empresas. Ainda há um longo caminho a ser percorrido neste setor, porém, é certo que passos importantes têm sido dados na direção correta e existem sinalizações claras de que os empresários vêm gradativamente incorporando o conceito de inovação nas suas agendas de investimentos. Enfim, a inovação tecnológica entrou definitivamente na agenda de nossas empresas e certamente contribuirá para torná-las mais competitivas, lucrativas e em condições de conquistar novos mercados. E finalmente o Brasil começa a formar uma nova geração de empresários empreendedores em tecnologia.

\section{Outras Prioridades do PACTI e Recursos}

Enquanto a Prioridades I e II do PACTI tinham caráter transversal, no sentido que cobriam todas as áreas do conhecimento e setores da economia, a Prioridade III, Pesquisa, Desenvolvimento e Inovação em Áreas Estratégicas, era voltada para o desenvolvimento de 13 áreas estratégicas: Áreas portadoras de futuro: Biotecnologia e Nanotecnologia; Tecnologias da Informação e Comunicação; Insumos para a Saúde; Biocombustíveis; Energia Elétrica, Hidrogênio e Energias Renováveis; Petróleo, Gás e Carvão Mineral; Agronegócio; Biodiversidade e Recursos Naturais; Amazônia e Semi-Árido; Meteorologia e Mudanças Climáticas; Programa Espacial; Programa Nuclear; e Defesa Nacional e Segurança Pública.

A Prioridade III, com seus 59 programas, representou $68 \%$ das atividades do PACTI, que receberam do MCT, no período 2007-2009, incluindo o FNDCT, recursos financeiros que totalizaram cerca de $\mathrm{R} \$ 3,0$ bilhões. Os resultados desses programas são bastante amplos e variados e mostram que todas as áreas tiveram seu desenvolvimento acelerado em razão do PACTI, podendo destacar alguns.

No âmbito das TICs o principal resultado foi a retomada do desenvolvimento na microeletrônica. Esta área, estratégica por conta de sua transversalidade em todos setores industriais, foi praticamente abandonada nas políticas de $\mathrm{C} \& \mathrm{~T}$ e industrial da década de 1990. O Programa Nacional de Microeletrônica, implantado em 2003, foi consolidado com a expansão do CI-Brasil, programa que está formando centenas de projetistas de circuitos integrados em dois centros de treinamento e 18 centros 
e design houses em todo o país, e com a criação da empresa pública CEITEC S.A. - Centro Nacional de Tecnologia Eletrônica Avançada, em Porto Alegre, vinculada ao MCT. A empresa CEITEC S.A foi implantada com investimentos do MCT de cerca de $\mathrm{R} \$ 500$ milhões, para construção e aquisição e instalação de equipamentos para um Centro de Projetos e uma fábrica de circuitos integrados, a primeira da América do Sul.

Entre os avanços conquistados na área de biocombustíveis merecem destaque a implantação da Rede de Bioetanol e a criação do Centro de Ciência e Tecnologia do Bioetanol (CTBE), instalado no campus do Laboratório Nacional de Luz Síncrotron, atualmente Centro Nacional de Pesquisa em Energia e Materiais, com objetivo de contribuir para a manutenção da liderança brasileira na produção sustentável de bioetanol da cana-de-açúcar. O CTBE recebeu investimentos de cerca de $\mathrm{R} \$ 100$ milhões e está realizando pesquisas com foco nos entraves agrícolas e tecnológicos dessa cadeia produtiva, tais como mecanização de baixo impacto para o plantio direto de cana-de-açúcar, com vistas à preservação do solo e à redução de custos no plantio e na colheita, e hidrólise enzimática da biomassa ligno-celulósica, além de modelagem, a exemplo da biorrefinaria virtual, e de estudos sobre sustentabilidade da produção de bioetanol.

Também deve ser destacada a criação da Rede Clima (Rede Brasileira de Pesquisa sobre Mudanças Climáticas), instituída pelo MCT em 2007, com o objetivo de gerar e disseminar conhecimento e tecnologia para que o Brasil possa responder às demandas e desafios representados pelas causas e efeitos das mudanças climáticas globais e embasar políticas brasileiras de prevenção, adaptação e mitigação. A abrangência da Rede CLIMA é nacional, envolvendo dezenas de grupos de pesquisa em universidades e institutos, e seu foco científico cobrirá todas as questões relevantes das mudanças climáticas, sejam referentes a setores ou sistemas: agricultura, biodiversidade, desastres naturais, energias renováveis, megacidades, políticas públicas, recursos hídricos, saúde humana e zonas costeiras. Até 2010 o MCT tinha investido $\mathrm{R} \$ 30$ milhões para a implantação da Rede CLIMA, além de ter contribuído com $\mathrm{R} \$ 35$ milhões, em conjunto com a FAPESP, para aquisição de um supercomputador para o Instituto Nacional de Pesquisas Espaciais (INPE), que entrou em operação em 2011. O novo supercomputador ampliou em mais de 50 vezes a capacidade de processamento no INPE e foi fundamental para o desenvolvimento e implementação do Modelo Brasileiro do Sistema Climático Global. Também foram investidos $\mathrm{R} \$ 7,2$ milhões no INCT para Mudanças Climáticas, o qual reúne cerca de 400 pesquisadores, estudantes e técnicos, de 76 grupos de pesquisa brasileiros e 19 estrangeiros.

Nos resultados da Prioridade IV do PACTI os principais destaques foram a Semana Nacional de Ciência e Tecnologia e a Olimpíada Brasileira de Matemática das Escolas Públicas. A Semana Nacional de Ciência e Tecnologia, realizada desde 
2004, é a principal iniciativa de popularização da ciência e tem contado com mobilização crescente em todo o País. Durante a Semana, em geral a segunda ou terceira do mês de outubro a cada ano, entidades de ensino e/ou pesquisa promovem atividades de divulgação da ciência, em suas instalações ou em espaços públicos.

Outro programa que chama atenção pelo êxito alcançado é a Olimpíada Brasileira de Matemática das Escolas Públicas (OBMEP), a principal ação para a melhoria do ensino de ciências. A OBMEP foi criada em 2005 para atender uma demanda do Presidente Lula, formulada quando tomou conhecimento que na tradicional Olimpíada de Matemática, realizada desde a década de 70, a participação de alunos de escolas públicas era insignificante, pois estes "não tinham coragem de enfrentar os alunos melhores preparados das escolas privadas". Naquele ano a OBMEP teve a participação de cerca de 10 milhões de estudantes e desde então o número de inscritos tem aumentado continuamente. Em 2010 a OBMEP teve quase 19,7 milhões de alunos inscritos, de 44.717 escolas em 99,4\% dos municípios brasileiros. As provas da OBMEP são feitas em três níveis, cobrindo desde a $5^{a}$ série do ensino fundamental até o ensino médio e são realizadas em duas etapas, a primeira de múltipla escolha e a segunda discursiva, esta para os $5 \%$ melhores classificados na primeira etapa. A realização da OBMEP só é possível graças à participação de um exército de 120 mil professores voluntários. Os alunos com as melhores notas recebem 3.000 medalhas, 300 de ouro, 900 de prata e 1.800 de bronze, e bolsas de iniciação científica júnior do $\mathrm{CNPq}$ para estudar matemática em programas extraclasse conduzidos por 200 centros de ensino em todo o País. A OBMEP tornou-se um grande programa mobilizador do ensino de matemática e que está tendo grande impacto na melhoria do ensino de ciências nas escolas públicas. O PACTI contribuiu decisivamente para a ampliação do orçamento do MCT, que como mostra a Figura 7 aumentou continuamente durante o Governo Lula.

A ampliação dos recursos federais para CT\&I, associada aos inúmeros programas articulados com os estados estimulam e viabilizam o aumento gradativo dos investimentos estaduais. Por outro lado, as medidas legais e iniciativas voltadas para incentivar as atividades de $\mathrm{P} \& \mathrm{D}$ e inovação nas empresas, levaram a um substancial aumento nos seus dispêndios em pesquisa e desenvolvimento (P\&D) e Inovação. Como resultado, os dispêndios nacionais em P\&D, somados os investimentos públicos, federal e estaduais, com os das empresas privadas, apresenta crescimento contínuo, como mostrado na Figura 9, demonstrando sua importância relativa na economia brasileira. Os dispêndios em $\mathrm{P} \& \mathrm{D}$ em relação ao Produto Interno Bruto (PIB), que historicamente no Brasil foram inferiores ou da ordem de 1\%, em 2007 foram de 1,07\% e alcançou 1,2\% em 2010. Esta taxa foi inferior a meta de 1,5\% do PIB prevista em 2007 para o PACTI por inúmeras razões. Uma 


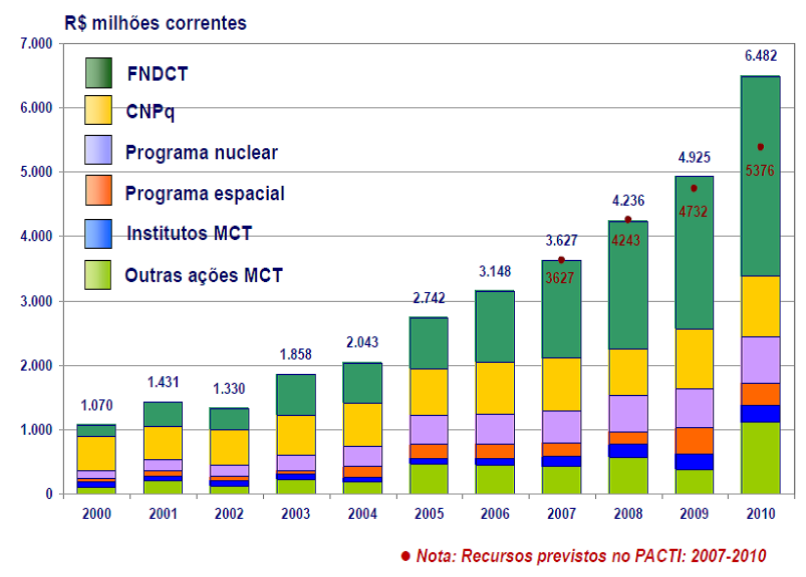

Figura 7: Evolução do orçamento de custeio e capital do MCT, em R \$ milhões correntes (não inclui despesas com pessoal). Uma das maiores contribuições para o aumento dos recursos federais para CT\&I foi o notável crescimento dos desembolsos pelo Fundo Nacional de Desenvolvimento Científico e Tecnológico (FNDCT), como mostrado na Figura 8. Este crescimento é resultado não apenas do aumento das receitas dos Fundos Setoriais, mas sobretudo pela decisão do Presidente Lula de gradualmente eliminar seu contingenciamento, medida praticada pela área econômica desde a criação dos Fundos.

delas é que ela foi concebida com base em valores do PIB divulgados à época, os quais eram menores do que os revisados posteriormente pelo IBGE. A outra foi a expansão aquém do previsto nos investimentos das empresas privadas.

O sucesso obtido na execução do PACTI indica o acerto no processo de sua formulação e na escolha das prioridades estratégicas, linhas de ação e programas. A execução do Plano de forma articulada, com antigos e novos parceiros do Sistema, resultou na construção de um arco de alianças que fortaleceu a posição central que Ciência, Tecnologia e Inovação devem ocupar no processo de desenvolvimento do País.

A aceleração no desenvolvimento científico e no processo de assimilação da necessidade em promover a inovação tecnológica nas empresas, proporcionado pelo PACTI, contribuiu para aumentar a percepção da sociedade brasileira do fato que CT\&I são, no cenário mundial contemporâneo, componentes essenciais para o desenvolvimento, o crescimento econômico, a geração de emprego e renda e a democratização de oportunidades. O trabalho de cientistas, engenheiros e de técnicos e o engajamento das empresas são fatores determinantes para a consolidação de um modelo de desenvolvimento sustentável, capaz de atender às justas demandas sociais dos brasileiros e ao permanente fortalecimento da soberania nacional. Esta é uma questão de Estado, que ultrapassa os governos. 


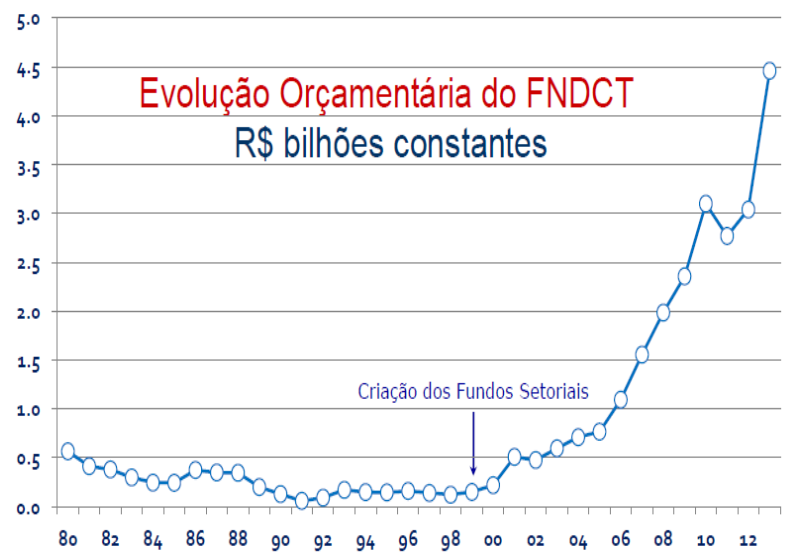

Figura 8: Evolução do Orçamento do Fundo Nacional de Desenvolvimento Científico e Tecnológico (FNDCT) (em R $\$$ bilhões constantes, corrigidos pelo IPCA no período 1971-2006, e R\$ bilhões correntes em 2007-2013.

É preciso reconhecer que os anos de 2011 e 2012 não foram tão favoráveis à Ciência e Tecnologia quanto os anteriores. Apesar do Governo Federal ter reafirmado a prioridade ao setor, explicitada na Estratégia Nacional de Ciência, Tecnologia e Inovação, formulada e anunciada em 2011, a crise econômica mundial afetou o financiamento do setor. Os orçamentos executados pelo Ministério da Ciência, Tecnologia e Inovação (MCTI) em 2011 e 2012 foram inferiores ao de 2010. A principal razão foi a queda do FNDCT, que voltou a ser contingenciado. Isto contribui para a contração do financiamento de muitos programas do MCTI e mesmo a paralização de alguns.

No que se refere à cooperação internacional, o Brasil tomou iniciativas relevantes e atendeu às demandas intensas nas atividades, hoje estratégicas, de cooperação internacional em ciência, tecnologia e inovação em diversas áreas do conhecimento. Fortaleceram-se os laços da colaboração Sul-Sul, em especial com Mercosul, América do Sul e outros países da América Latina, como Cuba. Foram ampliados os contatos e programas no âmbito da cooperação América do SulPaíses Árabes (ASPA) e com países africanos, em particular com a Comunidade de Países de Língua Portuguesa, especialmente na formação de recursos humanos e cooperação na construção de infra-estrutura de pesquisa. O Fórum IBAS e as relações com seus países (Índia, Brasil e África do Sul) avançaram consideravelmente, com a diversificação dos programas de trabalho. A cooperação com a China, além do bem-sucedido programa espacial, mobiliza novas áreas. Intensificou-se o trabalho conjunto com os países desenvolvidos, com destaque para Alemanha, França, União Européia, Estados Unidos, Reino Unido, Finlândia, Suíça, além de muitos outros, em programas essenciais de mútuo interesse. 


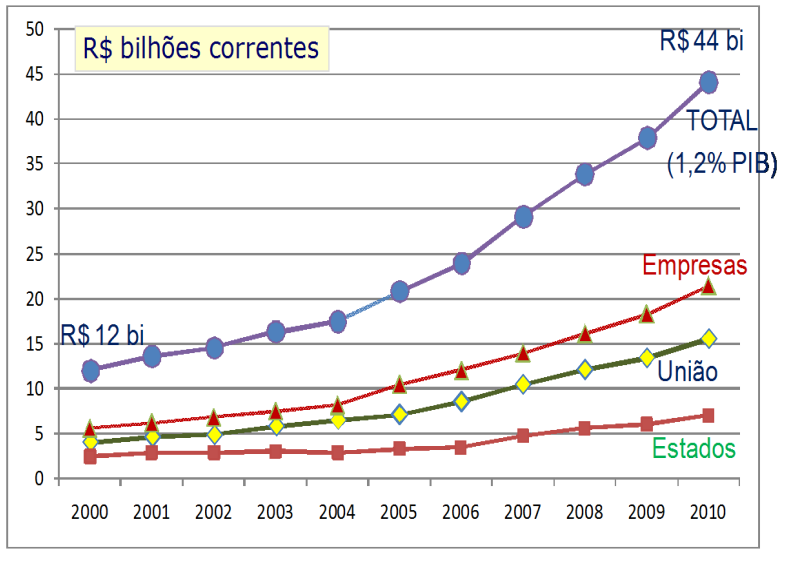

Fonte: Indicadores deC CI\&l, em www.mct.gov.br

Figura 9: Evolução dos dispêndios em $P \& D$ do governo federal, dos estados e das empresas em $\mathrm{R} \$$ bilhões correntes, no período 2000-2010.

Os programas de cooperação internacional ganharam nova perspectiva com a criação pela Presidente Dilma Roussef do Programa Ciência sem Fronteiras (CsF). Ele busca promover a consolidação, expansão e internacionalização da CT\&I e da competitividade brasileira por meio do intercâmbio e da mobilidade internacional. A iniciativa é fruto de esforço conjunto dos Ministérios da Ciência, Tecnologia e Inovação (MCTI) e do Ministério da Educação (MEC), viabilizada por meio de suas respectivas instituições de fomento, CNPq e Capes. O programa prevê a utilização de 100 mil bolsas em quatro anos para promover intercâmbio, de forma que alunos de graduação e pós-graduação façam estágio no exterior com a finalidade de manter contato com sistemas educacionais competitivos em relação à tecnologia e inovação. Além disso, busca atrair pesquisadores do exterior para visitar ou se fixar no Brasil, estabelecendo parcerias com os pesquisadores brasileiros nas áreas prioritárias do Programa, bem como criar oportunidade para que pesquisadores de empresas recebam treinamento especializado no exterior. O CsF está em execução plena e se constitui no programa mobilizador de maior sucesso nas últimas décadas, com grande repercussão no País e no Exterior.

\section{Cooperação entre o Brasil e Cuba}

Como mencionado anteriormente, Cuba foi um dos países com os quais o Brasil ampliou sua cooperação internacional durante o Governo de Presidente Lula. A intenção para viabilizar esta cooperação foi formalizada em 2010, quando uma delegação formada por pesquisadores e dirigentes de órgãos federais e chefiada pelo Ministro de C\&T do Brasil, fez uma visita oficial a Cuba. A delegação foi recepcionada pelo Dr. Fidel Castro Díaz-Balart, Conselheiro Chefe de Ciência e Tecnologia do Presidente Raúl Castro, e durante a visita foi assinado um Memorando de 
Entendimentos visando estabeler um intercâmbio de pesquisadores e estudantes em diversas áreas, dentre as quais Tecnologias da Informação, Nanotecnologia e Biotecnologia.

A escolha dessas áreas foi motivada por sua importância estratégica para o desenvolvimento, tanto de Cuba quanto do Brasil. A indústria brasileira de tecnologia da informação cresceu bastante na última década, sendo diversificada e sofisticada, porém voltada para atender a demanda local. Seu principal desafio é ampliar a participação no mercado global, num ambiente de grande abertura e internacionalização dos mercados, impulsionados pela Internet. Esta área também é importante para a modernização dos serviços e para o desenvolvimento de Cuba, e a cooperação com o Brasil poderá contribuir para vencer os principais desafios. A nanotecnologia, por sua vez, é estratégica para a inovação em vários setores da economia, tais como as indústrias de eletrônica, alimentos, têxteis, metal-mecânico, e energia, como também na agro-pecuária. Ela também terá aplicações transformadoras em áreas como a medicina e saúde pública, nas quais Cuba tem experiência exemplar. O Brasil já tem muitos grupos que trabalham em vários campos da nanotecnologia, enquanto Cuba implantou nos últimos anos um novo e moderno centro nesta área. Trata-se, portanto, de área na qual a cooperação entre os dois países poderá ser muito frutífera e contribuir para acelerar seu desenvolvimento em benefício das populações dos dois países. Finalmente, a biotecnologia, que é considerada uma das áreas mais promissoras entre os diversos desenvolvimentos tecnológicos emergentes, é essencial para tecnologias avançadas como genômica, proteômica e bioinformática, em seus diversos segmentos, que contribuem cada vez mais para o crescimento econômico e social das nações que detêm seu conhecimento. Plantas utilizadas como vacinas, vegetais enriquecidos com vitaminas, novos medicamentos produzidos por engenharia genética, órgãos e tecidos para transplante sem rejeição, microorganismos geneticamente modificados geneticamente para biorremediação e biomateriais de aplicação em saúde humana (nanomedicina) e de uso industrial (tecidos, plásticos vegetais e biodegradáveis, polímeros, produtos químicos e de eletrônica molecular), são alguns dos diversos exemplos dos avanços recentes. O Centro de Ingeniería Genética y Biotecnología de Havana tem destaque mundial nesta área enquanto o Brasil conta com grupos de nível internacional trabalhando em vários segmentos, e ambos os países têm muito a ganhar com a intensificação do intercâmbio.

Para concluir, mesmo com as históricas dificuldades políticas, econômicas e sociais, Brasil e Cuba construíram nas últimas quatro décadas suas comunidades científicas e tecnológicas com muitos milhares de mestres e doutores que realizam pesquisa em laboratórios com boas instalações de trabalho. Elas têm como desafio comum contribuir de forma decisiva para a realização de ambiciosos projetos de desenvolvimento de seus países. O reconhecimento que a intensificação da coo- 
peração científica e tecnológica poderá consolidar este processo, sem a necessidade da intermediação dos chamados países desenvolvidos, representa um grande avanço na relação entre os dois países. Passos concretos foram dados nesse sentido, que poderão servir de exemplo de cooperação Sul-Sul e ao mesmo tempo contribuir para aproximar os dois povos.

Recife, Olinda, Maceió, 2014 